\title{
Does Cognition Still Matter in Ethnobiology?
}

\author{
David Ludwig ${ }^{1 *}$ \\ ${ }^{1}$ Knowledge, Technology, and Innovation Group, Wageningen University and Research, Wageningen, Netherlands. \\ *david.ludwig@wur.nl
}

\begin{abstract}
Ethnobiology has become increasingly concerned with applied and normative questions about biocultural diversity and the livelihoods of local communities. While this development has created new opportunities for connecting ethnobiological research with ecological and social sciences, it also raises questions about the role of cognitive perspectives in current ethnobiology. In fact, there are clear signs of institutional separation as research on folkbiological cognition has increasingly found its home in the cognitive science community, weakening its ties to institutionalized ethnobiology. Rather than accepting this separation as inevitable disciplinary specialization, this short perspective article argues for a systemic perspective that addresses mutual influences and causal entanglement of cognitive and non-cognitive factors in socioecological dynamics. Such an integrative perspective requires a new conversation about cognition in ethnobiology beyond traditional polarization around issues of cognitive universals and cultural relativity.
\end{abstract}

Received June 22, 2018

OPEN ӘACCESS

Accepted August 31, 2018

DOI 10.14237/ebl.9.2.2018.1350

Keywords Cognitive ethnobiology, Cognitive science, Ethnobiology 5, Applied ethnobiology, Ethnobiological theory, Interdisciplinarity

Copyright (C) 2018 by the author(s) licensee Society of Ethnobiology. This is an open-access article distributed under the terms of the Creative Commons Attribution-NonCommercial 4.0 International Public License (https://creativecommons.org/licenses/by-nc/4.0), which permits non-commercial use, distribution, and reproduction in any medium, provided the original author and source are credited.

\section{Introduction}

Ethnobiology is commonly defined as a transdisciplinary field that integrates heterogenous methods from biological taxonomy and cognitive science to political ecology and Indigenous studies. Despite this transdisciplinary identity (e.g., Anderson 2012; Wolverton 2013), the current state of ethnobiology is far from unified as researchers tend to prioritize methodological perspectives along their heterogenous disciplinary backgrounds. In the United States, much of the institutionalization of ethnobiology coincided with the emergence of the cognitive sciences and was entangled with more general ambitions of cognitive anthropology and ethnoscience (Hunn 2007). Just as the "cognitive revolution" motivated the search for linguistic and psychological universals, much of American ethnobiology in the 1960s and 1970's aimed for universals in human reasoning about the biological world (Ludwig 2018). In fact, the influence of these cognitivist concerns became so dominant that Hunn (1982:831) argued for a reconsideration of the "utilitarian factor" and suggested that "the fact that cultural knowledge of the natural world might also be of use practically has been treated [...] almost as an embarrassment".

The institutional dynamics in ethnobiology have changed rather dramatically since the early 1980s. While ethnobiology has become less engaged with general debates about cognitive universality and cultural relativity, new research priorities have emerged around issues such as agroecology, climate change, conservation management, food security, knowledge rights, and political self-determination (Nabhan et al. 2011). Following Hunn's (2007) periodization of four phases in ethnobiology, Wyndham et al. (2011:124) therefore envision the development of an "ethnobiology 5 " in which "the field plays a heightened role in addressing the needs of a world coping with rapid ecological change and shifting political economies". Furthermore, Wolverton (2013:22) specifies this idea of an emerging fifth phase that creates an "expansive future for ethnobiology [...] beyond its traditional disciplinary homes in anthropology and biology, moving toward human geography, environmental philosophy, political ecology, conservation biology, and related fields with more explicit ideological missions." 
The absence of any cognitive and psychological research in Wolverton's list of disciplines is not surprising but reflects a shift in emphasis toward applied and normative concerns in ethnobiology. Furthermore, the decisively local character of many of these concerns tends to motivate questions about the particularities of specific socio-ecological systems rather than questions about cross-cultural invariance and underlying cognitive structures. For example, concerns about food security of a particular Indigenous community will often connect more straightforwardly to the economics of agricultural intensification, the dynamics of soil degradation, and the politics of Indigenous self-determination rather than questions about the universality of the categorization of plants or cross-cultural invariance of inductive reasoning about causality.

One consequence of this development is a striking absence of cognitive perspectives in many characterizations of the state and future of ethnobiology. This does not mean that cognitivist research on folkbiology has vanished. Although questions about folkbiological cognition appear increasingly relegated to the periphery of "ethnobiology 5", they have found a new institutional home in the cognitive sciences and have been connected to heterogenous issues from foundational debates about cognitive modularity (Atran and Medin 2008) and essentialism (Gelman 2003; Sousa et al. 2002) to their implications for issues such as childhood anthropocentrism (Waxman and Medin 2007), learning about environments (Zarger 2011), or folk categories of race (Machery and Faucher 2005).

For example, consider Atran and Medin's influential research program that integrates ethnobiological concerns with debates about the modular structure of human cognition and the specific hypothesis of an innate module of folkbiological cognition. While their synthesizing The Native Mind (2008) has been widely discussed in the cognitive sciences (e.g., Bender and Beller 2011; Glushko 2008; Keil 2010; Waxman et al. 2014), there is a striking absence of substantial engagement in journals and conferences of institutionalized ethnobiology. Four decades after Hunn warned about a neglect of the "utilitarian factor" through the dominance of cognitivist perspectives, it has therefore become time to invert his warning by reconsidering the role of the "cognitive factor" in an ethnobiological community that has shifted its focus increasingly towards applied and normative concerns.

While some of these developments are unique to the ethnobiology community, they also need to be situated in more general dynamics of institutional separation that reflect conflicting ideas about the role of cognition in the human sciences. For example, shifting attitudes toward cognitive factors in ethnobiology are closely entangled with the changing relationship between anthropology and the cognitive sciences. While the emergence of cognitive ethnobiology in the United States was part of a larger trend towards cognitive anthropology during the "cognitive revolution" of the 1960s (Hunn 2007), the position of anthropology in the cognitive sciences has become increasingly precarious. For example, Beller et al. (2013) ask whether anthropology should be still considered part of cognitive science and emphasize that the dominance of cognitive psychology has marginalized field work-based methods and ethnographic description beyond the lab. As a result, Beller et al. diagnose that "anthropology is deserting, and is being deserted by, the other cognitive sciences just at the point where the role of culture is increasingly recognized as of prime relevance for the science of human cognition" (2013:343).

While there is a story about the marginalization of anthropology in cognitive science, there is also an inverted story about the marginalization of cognitive perspectives in anthropology. Simultaneously to the institutionalization of the cognitive sciences, anthropology increasingly developed an identity as a discipline that addresses culture "not [as] an experimental science in search of law but [as] an interpretive one in search of meaning" (Geertz 1973:5). Geertz's influential account of "thick description" explicitly positioned itself in contrast to both ethnoscience and cognitive anthropology. As Hunn (2018:427) argues, "the cognitive foundations of culture - the heart of the cognitive anthropology of the 1960s and 1970s - was dismissed as 'psychology' and thus not properly 'cultural' (Geertz 1973:11). The subsequent postmodern turn abandoned formal comparative empirical research-the hallmark of cognitive anthropology - in favor of hermeneutics."

Of course, there has never been a complete isolation of anthropology from cognitive perspectives with researchers from Bateson (1972) and Ingold (2000) to Ellen (2006) and Bloch (2012) developing 
various integrative programs. However, there still remains a clear case for mutual marginalization in the mainstream of both disciplines that can provide instructive lessons for the current state of ethnobiology. First, ethnobiology may be on an analogous path of institutional separation that leaves cognitive and non-cognitive research increasingly isolated from each other. Furthermore, one may embrace this separation as a tense but ultimately necessary process of disciplinary specialization. Ethnobiologists share a focus on the relations between local communities, biota, and environments, but researchers from different fields have very different questions about these relations that demand equally different methods. A botanist may wonder whether ethnotaxa can guide the identification of new species with DNA barcoding methods. A political ecologist may wonder how agricultural intensification interacts with labor conditions of an Indigenous community. A cognitive psychologist may wonder whether cross-cultural comparisons of ecological reasoning can shed light on human adaptation to complexity and uncertainty. These questions can all guide legitimate research projects even if they ultimately have relatively little to contribute to each other.

There are some important lessons in this case for disciplinary specialization and a more resolute pluralism about disciplinary concerns can avoid unproductive priority disputes between ethnobiologists with different disciplinary backgrounds. However, an entirely fragmented vision of ethnobiology also obscures why ethnobiology matters in the first place. One does not need to embrace a fully unified vision of ethnobiology to think that the field should aim for more than only the sum of insights from its disciplinary parts. Indeed, a core motivation for ethnobiological research is the recognition that many relevant issues can only be addressed through the entanglement of biological, cognitive, and sociocultural factors that remain isolated in more narrow disciplinary research. Dynamics of "biocultural" (Wyndham et al. 2011) or "socio-ecological" (Hidayati et al. 2015) systems can only be understood if the causal interaction of highly heterogeneous factors such as soil chemistry, spiritual beliefs, economic pressures, plant categories, deforestation, agricultural practices, ecological reasoning, and migration patterns are taken into account.
If such a systemic perspective on the interaction between biological, cognitive, and sociocultural factors is a core task of ethnobiology, an isolation of cognitive perspectives from the applied and normative concerns of "ethnobiology 5" runs the risk of undermining the raison d'etre of ethnobiology through disciplinary fragmentation. And indeed, there is an alternative way of thinking about the role of cognition in ethnobiology that recognizes the value of disciplinary specialization but also the relevance of investigating the entanglement of cognitive factors and wider dynamics in socio-ecological systems. A systemic perspective on causal interactions between biological, cognitive, and sociocultural factors provides opportunities for more integrative research but also comes with challenges for researchers with different disciplinary perspectives. First, there is the challenge of overcoming stereotypes of cognitive science as antagonistic to applied and normative concerns about local socio-ecological dynamics. A sufficiently rich understanding of such dynamics requires attention to the causal roles of cognitive factors through categorization, reasoning, and perception that often remain neglected because of disinterest or even hostility towards cognitive perspectives in discourses of cultural anthropology and social sciences.

At the same time, such an integration also requires that cognitive scientists take the systemic character of multi-directional causal interactions seriously rather than focusing on the priority of cognitive factors as the foundation upon which sociocultural diversity is built. Of course, there are plenty of cases in which cognitive factors ground sociocultural phenomena just as there are cases in which sociocultural factors shape cognitive phenomena. However, there are clear limitations of cognitivist programs that think of themselves primarily as providing the universal foundations upon which cultural diversity is built. First, negotiations of priority encourage ideological (e.g., "cognitivist" vs. "culturalist") confrontations about the relation between disciplines and methodologies. If the interaction between biological, cognitive, and sociocultural factors is approached through questions of priority, there is little hope that the heterogeneous community of ethnobiologists can find a common starting point.

Second, priority questions often obscure the reciprocal character of causal interactions in socio- 
ecological systems that can be empirically explored without settling general disputes about cognitivist and culturalist programs. While it is true that many prominent cognitivist approaches develop ambitious foundational programs from Berlin et al.'s (1973) general principles of classification to Atran and Medin's (2008) biological module of the mind, many of their insights can be appreciated without commitment to their entire theoretical frameworks and without getting stuck in general controversies about the merits of universalism and relativism. For example, substantial parts of Atran and Medin's work (e.g., on devolution of biological knowledge, about inductive reasoning, or about folkecology) provide important lessons for ethnobiologists no matter where they stand in ongoing controversies about the "modularity of mind" (Barrett 2105). Rival (2018:428) is therefore entirely right to emphasize that "Atran's and Medin's highly original programme" deserves more attention in ethnobiology because it is concerned "with the pragmatics of reasoning in the fire of social action."

To illustrate this point, consider Atran and Medin's (2008) folkecological research on cognitive strategies in agroforestry regimes in the Guatemalan lowlands of El Petén. Addressing cognitive and sociocultural factors in agroforestry practices of three communities (native Itza' Maya, Spanish-speaking immigrant Ladinos, and immigrant Q'eqchi' Maya), Atran and Medin develop a complex picture of the relation between biological, cognitive, and sociocultural factors. Given rapid deforestation in El Petén, one of their core findings is that native Itza' Maya practiced sustainable agroforestry while immigrant Q'eqchi' Maya practices were largely insensitive to the long-term survival of the lowland forest. Cognitive factors come into play as a partial explanans for these differences as Itza' and Q'eqchi' employed different mental models with equally different assumptions about the relation between animals, plants, and humans. For example, there were not only substantial quantitative but also qualitative differences in Itza' and Q'eqchi' reasoning about ecological relations between animals and plants. While Q'eqchi' understood these relations as unidirectional with plants providing food for animals, Itza' emphasized their reciprocal character with animals affecting plants in multiple ways such as seed dispersal and fertilization.
While cognitive factors contribute to the explanation of Itza' and Q'eqchi' agroforestry, they can themselves be partly explained in terms of different sociocultural practices. Atran and Medin found that Itza' culture emphasizes and strongly values expertise about the forest in a way that "information about the forest appears integrally bound to intimate patterns of social life as well as to an experiential history traceable over many generations" (2008:212). In the context of Q'eqchi' communities, Atran and Medin did not find similar sociocultural patterns and they argue that "continued corporate and ceremonial ties to the sacred mountain valleys of the Q'eqchi' highlands do not imply a corresponding respect for lowland ecology" (2008:212). In other words, their comparative study does not only address the role of cognitive factors in affecting ecological phenomena but also accounts for the role of sociocultural factors in affecting cognitive phenomena. Furthermore, these sociocultural factors are themselves not brute facts but can be related back to factors such as the adaptation of Itza' and Q'eqchi' cultures to their native lowland and highland environments.

Several lessons can be drawn from this short example. First, cognitive factors matter for applied and normative concerns about local environments and livelihoods that drive "ethnobiology 5". Differences in mental models and ecological reasoning guided Itza" and Q'eqchi' interactions with the forest and a neglect of these factors obscures important causal factors for understanding agroforestry practices. Indeed, this point is not restricted to Atran and Medin's work in Guatemala but has emerged from many other studies on folkbiological categories. For example, Medin et al.'s (2006) study of the folkbiology of freshwater fish starts with traditional concerns in cognitive ethnobiology about category formation but explores how differences in categorization of fish interact with ecological expertise. Furthermore, one can find similar lessons in other areas of research including Berkes' (2018) classical articulation of "Traditional Ecological Knowledge" that is highly sensitive to how local categories-including the infamous "Eskimo word for snow" - can function as repositories of ecological knowledge. Finally, consider Anderson's (1996) discussion of feng-shui as an "ecology of the heart" that relies on the interaction between cognitive 
and emotional factors in co-producing Chinese practices of landscape planning through aesthetic perception and care. All of these studies share the basic insight that investigation into cognitive factors such as categorization, perception, and reasoning is often of crucial relevance for understanding applied issues such as sustainable hunting, farming, and fishing practices. A general neglect of cognitive factors would therefore not advance but rather obstruct the applied and normative agendas of "ethnobiology 5".

A second lesson from Atran and Medin's case study is the importance of a systemic perspective on mutual influences and causal feedback loops rather than linear priority ordering. In the case of Itza' and Q'eqchi' agroforestry, for example, cognitive and ecological factors can both be cause and effect for each other. On the one hand, Atran and Medin's analysis of mental models addresses how cognitive factors guide local interventions in ecosystems. On the other hand, differences in mental models are not only causes but also effects of ecological phenomena as Itza' and Q'eqchi' reasoning has been shaped by their native lowland and highland environments. Similar cases for mutual influence can be made with regard to sociocultural factors such as Itza' accounts of forest spirits that shape agroforestry practices but can also be described as being shaped by cognitive and ecological factors such as the pressure to adapt a sustainable use of forest resources (see also Albuquerque et al. 2015). Understanding of Itza' and Q'eqchi' agroforestry therefore requires modeling of a complex system of interacting causal factors rather than linear ordering of causal factors through cognitive foundations of sociocultural phenomena (or vice versa).

Third, many of these dynamics can be empirically investigated without requiring prior agreement about foundational controversies about issues such as cognitive universals and cultural relativism. For example, much of Atran and Medin's analysis of Itza' and Q'eqchi' reasoning can be appreciated without agreement on their general nativist framework of modularity of mind. The applied and normative concerns of ethnobiology 5 often require close attention to cognitive factors but much of the relevant evidence about local categorization, reasoning, and perception can be integrated in different theoretical frameworks. Of course, this does not mean that these theoretical frameworks are without practical relevance and foundational assumptions about cognitive universals and cultural relativity will clearly affect modeling of causal pathways between interacting factors. However, it is simply a mistake to assume that no progress can be made until everyone agrees on these issues.

This short perspective article has argued that we need a new conversation about cognition in ethnobiology that challenges the increasing institutional separation between cognitive perspectives on folkbiology and normative concerns of "ethnobiology 5". By proposing a systemic perspective that focuses on multi-directional causal interactions, the article sketched an alternative to priority disputes about the relation between biological, cognitive, and sociocultural factors. Such an integrative perspective can lead not only to more adequate models of socio-ecological dynamics but also provide opportunities for better connecting ethnobiology with the state of both cognitive sciences and anthropology.

Current developments in the cognitive sciences can provide ethnobiologists with fruitful theoretical resources as illustrated by the increased prominence of research on cognitive diversity across cultures (Bender and Beller 2016; Henrich et al. 2010) and extensive debates about embodied, embedded, and situated cognition (Shapiro 2014). This literature demonstrates that the current state of the cognitive sciences has much more to offer to current ethnobiology than a continuation of tired controversies about universalism vs. relativism. Instead, a vast body of empirical research has come to focus on cognitive processes within local contexts and provides currently underexplored resources for addressing cognitive factors in socio-ecological dynamics as well as their implications for issues such as agricultural and conservation practices in ethnobiology.

Further impulses for a novel conversation about cognition can be found in anthropological theory. For example, Ingold (2000:167) has emphasized the practical significance of cognitive factors and argued for the need to "re-embed perception and cognition within the practical contexts of people's ongoing engagement with their environments in the ordinary course of life." While such a practice-oriented perspective on cognition is rarely explored in ethnobiology (interesting exceptions include Rival 2014; Villagómez-Reséndiz 2017), it provides 
resources for bridging overly abstract cognitivist approaches and theoretically underdeveloped discussions in applied ethnobiology. Furthermore, following Ingold's practice-oriented focus on cognition also provides a novel angle for connecting ethnobiological research to current controversies about the "ontological turn" (see also Daly et al. 2016; Ludwig 2016) that engage with issues such as the boundaries of cognition in animist perspectives (Descola 2013, Kohn 2013, Viveiros de Castro 2012).

To sum up, a reconsideration of cognitive factors does not undermine the applied and normative concerns of "ethnobiology 5". On the contrary, a novel conversation about cognition can provide ethnobiologists with crucial resources for understanding socio-ecological dynamics and for integrating their research with wider debates from "situated cognition" to the "ontological turn".

\section{Declarations}

Permissions: None declared.

Sources of Funding: None declared.

Conflicts of Interest: None declared.

\section{References Cited}

Albuquerque, U. P., P. M. Medeiros, and A. Casas.

2015. Evolutionary Ethnobiology. Springer International Publishing, Switzerland.

Anderson, E. N. 2011. Ethnobiology: Overview of a Growing Field. In Ethnobiology, edited by E. N. Anderson, D. Pearsall, E. Hunn, and N. Turner, pp.1-14. Wiley-Blackwell, New York, NY.

Anderson, E. N. 1996. Ecologies of the Heart: Emotion, Belief, and the Environment. Oxford University Press, Oxford, UK.

Atran, S., and D. L. Medin. 2008. The Native Mind and the Cultural Construction of Nature. MIT Press, Cambridge, MA.

Barrett, H. C. 2015. Modularity. In: Evolutionary Perspectives on Social Psychology, pp. 39-49. Springer, Dordrecht, Netherlands. DOI:10.1007/978-3-31912697-5.

Bateson, G. 2000. Steps to an Ecology of Mind. University of Chicago Press, Chicago, IL.

Beller, S., A. Bender, and D. L. Medin. 2012. Should Anthropology be Part of Cognitive Science? Topics in Cognitive Science 4:342-353. DOI:10.1111/j.17568765.2012.01196.x.
Bender, A., and S. Beller. 2011. The Cultural

Constitution of Cognition. Frontiers in Psychology 2:67. DOI:10.3389/fpsyg.2011.00067.

Bender, A., and S. Beller. 2016. Current Perspectives on Cognitive Diversity. Frontiers in Psychology 7:509. DOI:10.3389/fpsyg.2011.00067.

Berkes, F. 2018. Sacred Ecology. Routledge, New York, NY.

Berlin, B., D. Breedlove, and P. Raven. 1973. General Principles of Classification and Nomenclature in Folk Biology. American Anthropologist 75:214-242. DOI:10.1525/aa.1973.75.1.02a00140.

Bloch, M. 2012. Anthropology and the Cognitive Challenge. Cambridge University Press, Cambridge, UK.

Daly, L., K. French, T. L. Miller, and L. Nic Eoin. 2016. Integrating Ontology into Ethnobotanical Research. Journal of Ethnobiology 36:1-9. DOI:10.2993/0278-0771-36.1.1.

Descola, P. 2013. Beyond Nature and Culture. University of Chicago Press, Chicago, IL.

Ellen, R. 2006. The Categorical Impulse. Berghahn Books, Oxford, UK.

Geertz, C. 1973. The Interpretation of Cultures. Basic Books, New York, NY.

Gelman, S. A. 2003. The Essential Child: Origins of Essentialism in Everyday Thought. Oxford University Press, Oxford, UK.

Glushko, R. J., P. P. Maglio, T. Matlock, and L. W. Barsalou. 2008. Categorization in the Wild. Trends in Cognitive Sciences 12:129-135. DOI:10.1016/ j.tics.2008.01.007.

Henrich, J., S. J Heine, and A. Norenzayan. 2010. The Weirdest People in the World? Behavioral and Brain Sciences 33:61-83. DOI:10.1017/ S0140525X0999152X.

Hidayati, S., F. M. Franco, and R. W. Bussmann. 2015. Ready for Phase 5-Current Status of Ethnobiology in Southeast Asia. Journal of Ethnobiology and Ethnomedicine 11:17. DOI:10.1186/ s13002-015-0005-7.

Hunn, E. 1982. The Utilitarian Factor in Folk Biological Classification. American Anthropologist 84:830-847.

Hunn, E. 2007. Ethnobiology in Four Phases. Journal of Ethnobiology 27:1-10. DOI:10.2993/0278-0771 (2007)27[1:EIFP]2.0.CO;2. 
Hunn, E. 2018. Comment on Ludwig "Revamping the Metaphysics of Ethnobiological Classification". Current Anthropology 59:415-438.

DOI:10.1086/698958.

Ingold, T. 2000. The Perception of the Environment. Routledge, New York, NY.

Keil, F. C. 2013. The Roots of Folk Biology. Proceedings of the National Academy of Sciences 110:15857-15858. DOI:10.1073/pnas.1315113110.

Kohn, E. 2013. How Forests Think. University of California Press, Berkeley, CA.

Ludwig, D. 2016. Overlapping Ontologies and Indigenous Knowledge. From Integration to Ontological Self-Determination. Studies in History and Philosophy of Science Part A, 59:36-45. DOI:10.1016/j.shpsa.2016.06.002.

Ludwig, D. 2018. Revamping the Metaphysics of Ethnobiological Classification. Current Anthropology 59:415-438. DOI:10.1086/698958.

Machery, E., and L. Faucher. 2005. Social Construction and the Concept of Race. Philosophy of Science 72:1208-1219. DOI:10.1086/508966.

Medin, D. L., N. O. Ross, S. Atran, D. Cox, J. Coley, J. B. Proffittand, and S. Blok. 2006. Folkbiology of Freshwater Fish. Cognition 99:237-273. DOI:10.1016/j.cognition.2003.12.005.

Nabhan, G. P., F. Wyndham, and D. Lepofsky. 2011. Ethnobiology for a Diverse World Ethnobiology Emerging From a Time of Crisis. Journal of Ethnobiology 31:172-175. DOI:10.2993/0278-077131.2.172.

Rival, L. 2014. Encountering Nature through Fieldwork: Expert Knowledge, Modes of Reasoning, and Local Creativity. Journal of the Royal Anthropological Institute 20:218-236. DOI:10.1111/1467-9655.12101.

Rival, L. 2018. Comment on Ludwig "Revamping the Metaphysics of Ethnobiological Classification". Current Anthropology 59:415-438. DOI:10.1086/698958.
Ross, N., and C. Revilla-Minaya. 2011. Cognitive Studies in Ethnobiology: What Can We Learn About the Mind as Well as Human Environmental Interaction? In Ethnobiology, edited by E. N. Anderson, D. Pearsall, E. Hunn, and N. Turner, pp. 335-349. Wiley-Blackwell, New York, NY.

Shapiro, L., ed. 2014. The Routledge Handbook of Embodied Cognition. Routledge, New York, NY.

Sousa, P., S. Atran, and D. Medin. 2002. Essentialism and Folkbiology: Evidence from Brazil. Journal of Cognition and Culture 2:195-223. DOI:10.1163/15685370260225099.

Villagómez-Reséndiz, R. 2017. Hacia una Etnobiología Cognitiva: Tecnología Hidráulica Mesoamericana y Cognición en los Altos de Morelos. Etnobiología 15:89-98.

Viveiros de Castro, E. 2012. Cosmological Perspectivism in Amazonia and Elsewhere. HAU Masterclass Series, Manchester, UK.

Waxman, S., and D. Medin. 2007. Experience and Cultural Models Matter: Placing Firm Limits on Childhood Anthropocentrism. Human Development 50:23-30. DOI:10.1159/000097681.

Waxman, S. R., P. Herrmann, J. Woodring, and D. Medin. 2014. Humans (Really) are Animals: Frontiers in Psychology 5:172. DOI:10.3389/fpsyg.2014.00172.

Wolverton, S. 2013. Ethnobiology 5: Interdisciplinarity in an Era of Rapid Environmental Change. Ethnobiology Letters 4:21-25. DOI:10.14237/ ebl.4.2013.11.

Wyndham, F. S., D. Lepofsky, and S. Tiffany. 2011. Taking Stock in Ethnobiology: Where Do We Come From? What Are We? Where Are We Going? Journal of Ethnobiology 31:110-127. DOI:10.2993/0278-0771-31.1.110.

Zarger, R. K. 2011. Learning Ethnobiology: Creating Knowledge and Skills About the Living World. In Ethnobiology, edited by E. N. Anderson, D. Pearsall, E. Hunn, and N. Turner, pp. 371-386. WileyBlackwell, New York, NY. 